BULLETIN Bulletin hispanique

HISPANIQUE Université Michel de Montaigne Bordeaux

$110-2 \mid 2008$

Varia

\title{
El Veintisiete propio y extraño de Ángel Valbuena Prat: Calderón vs. Góngora
}

Enrique Serrano Asenjo

\section{(2) OpenEdition}

Journals

Edición electrónica

URL: http://journals.openedition.org/bulletinhispanique/769

DOI: 10.4000/bulletinhispanique.769

ISSN: 1775-3821

Editor

Presses universitaires de Bordeaux

Edición impresa

Fecha de publicación: 1 diciembre 2008

Paginación: 513-535

ISBN: 978-2-86781-543-0

ISSN: 0007-4640

Referencia electrónica

Enrique Serrano Asenjo, «El Veintisiete propio y extraño de Ángel Valbuena Prat: Calderón vs. Góngora », Bulletin hispanique [En línea], 110-2 | 2008, Publicado el 01 diciembre 2011, consultado el 20 abril

2019. URL : http://journals.openedition.org/bulletinhispanique/769; DOI : 10.4000/

bulletinhispanique.769

Tous droits réservés 


\title{
El Veintisiete propio y extraño de Ángel Valbuena Prat: Calderón vs. Góngora ${ }^{1}$
}

\author{
Enrique Serrano Asenjo \\ Universidad de Zaragoza - España
}

Para K. M. Sibbald

Le présent article étudie les textes que le critique, poète et écrivain Ángel Valbuena Prat consacre à la "Génération de 27" depuis sa contribution à la célébration du tricentenaire de la mort de Góngora en 1927. Il accorde une attention toute particulière à sa célèbre Historia de la literatura española $\left(1968,8^{e}\right.$ ed.). Le récit constitué à partir de telles sources constitue un fragment, particulièrement digne d'intérêt, de l'autobiographie de l'auteur, qui s'est toujours considéré comme l'un des membres du groupe. Ce récit présente aussi des similitudes avec le «roman lyrique». Certaines des tensions internes qui caractérisent ce dernier, comme certains blancs, réticences ou démentis, nous amèrent à poser le problème de l'opposition de fond entre d'une part, la "Génération de 27" officielle, celle de la poésie pure et de la deshumanisation de l'art, qui célèbre Góngora, et celle, intimement défendue par Valbuena, humaniste et humaine, qui célèbre Calderón.

1. Este trabajo se ha realizado en el marco del proyecto de investigación «Corpus de noticias e ideas relativas a la historiografía literaria española», HUM 2005/06063, dirigido por el Dr. Leonardo Romero Tobar y con una ayuda de la Secretaría de Estado de Universidades e Investigación, del Ministerio de Ciencia y Tecnología.

$B H i$, Tome $110, \mathrm{n}^{\circ} 2$ - décembre 2008 - p. 513 à 535. 
El artículo estudia los textos que el crítico y creador Ángel Valbuena Prat dedicó a la "Generación del 27", desde sus contribuciones a la celebración del centenario de Góngora en 1927 y con atención especial a su conocida Historia de la literatura española (1968, $8^{a}$ ed.). El relato que conforman dichas fuentes resulta un fragmento destacado de la autobiografía del autor, pues siempre se consideró uno de ellos, y presenta puntos en común con el género de la novela lírica. Determinadas tensiones internas del mismo, como ciertos vacios, reticencias y casi desmentidos, nos llevan a plantear el enfrentamiento de fondo entre el Veintisiete oficial, gongorino, el de la poesía pura y la deshumanización del arte, por un lado; y por otro, el intimamente respaldado por Valbuena, calderoniano, humanista $y$ humano.

This article analyses the texts that the critic, poet and writer Angel Valbuena Prat wrote on "the Generation of 27'", from his contribution to Góngora's death tercentenary celebration in 1927 on. It pays special attention to his well-known 'Historia de la Literatura Española' (1968, $8^{\text {th }}$ edition). This account, composed of such sources, is an outstanding fragment in the writer's autobiography, as he always considered himself a member of the group. It also shares some of the features common to the genre of the "lyric novel". Some of the inner tensions that are characteristic of this account, as well as certain gaps, reservations or almost denials, bring us to question what can be seen as a clash between, on the one hand, the official version of the "Generation of 27", the 'Gongorine', that of pure poetry and dehumanization of art, and, on the other hand, the one deeply supported by Valbuena, humanistic and human, the 'Calderonian'.

Mots-clés: Ángel Valbuena Prat - Historiographie littéraire - $\mathrm{XX}^{\mathrm{e}}$ siècle - «Génération de 27» - Déshumanisation de l'art - Poésie pure - Réception de Góngora - Réception de Calderón.

$\mathrm{E}$ L OBJETIVo de este trabajo consiste en analizar el funcionamiento del relato que Ángel Valbuena Prat, crítico y creador coetáneo del 27, elabora acerca de dicho grupo en el conjunto de su trayectoria y especialmente en su Historia de la literatura española (1968, 8a ed.). Se trata de comprender mejor el proceso de canonización del grupo, autocanonización sería más preciso (Anderson, 2005, 336), a partir de un autor de gran prestigio e influencia en la historiografía literaria de la centuria anterior, pero no por ello exento de las tensiones que conlleva el hecho de compartir una misma edad y palestra intelectual y, a la vez, adoptar planteamientos estéticos no siempre coincidentes y en ocasiones sencillamente discrepantes con los que el 27 oficial vendría a encarnar. Así pues, intentamos un ejercicio de metahistoria (Santiáñez-Tió, 1997, 287), que pondrá de relieve que, como ha subrayado 
Linda Hutcheon (2002, 7), las historias literarias confieren legitimidad; mas se trata de una legitimidad que puede entrańar inestabilidades diversas, especialmente acusadas cuando se aborda lo contemporáneo y todavía más cuando lo que está en juego es el retrato de la propia vida de quien cuenta el pasado próximo: «esa Historia (...) va íntimamente, subjetivamente unida al hombre Ángel Valbuena, que la creó, pero también la recreó a lo largo de cuarenta ańos de trayectoria vital» (Palomo y Prieto, 2000, 17).

Ángel Valbuena Prat (Barcelona, 1900-Madrid, 1977) ha pasado a la historia de la literatura espańola como un filólogo destacado, lo certifica Ángel del Río, el «otro» historiador literario entre los del 27 (Río, 1982, 515; cfr. Serrano Asenjo, 2004). Junto a esa faceta del personaje, hay que tener en cuenta su dimensión como creador, sobre todo desarrollada en los años veinte y treinta. Es autor de dos volúmenes en prosa: Teófilo. Esbozo de una vida 1898-1925 (1926) y 2 + 4. Relatos de misticismo y de ensueño (1927), novelas «líricas e intelectuales» según Eugenio de Nora (1973, 240; cfr. Bonet, 1995, 607), que encierran una educación sentimental expresada con desusada comparecencia de corrientes literarias a la hora de caracterizar a los héroes (realismo, romanticismo, renacimiento o barroco). Pues bien, en su reseña de $2+4$, un lector tan competente en lides de modernidad como Agustín Espinosa advertía en el texto una tendencia nueva, «sin precedentes en la literatura contemporánea: el neo-calderonismo» (1927, 17). Así daba razón, por ejemplo, de «Los caminos del hombre (Auto sacramental alegórico)». No se pierda de vista que la tesis doctoral del autor versó sobre el dramaturgo de La vida es sueño y se había publicado en las páginas de la Revue Hispanique (LXI, 1924) como «Los autos sacramentales de Calderón: Clasificación y análisis» (Díez de Revenga, 1977, 39).

La poesía de Valbuena a la sazón ofrece mayor diversidad de perfiles, si bien un cierto telón de fondo seiscentista preside en mayor o menor medida sus composiciones coetáneas. Lo comprobamos desde los textos religiosos, que suponen una nueva constante de su producción poética, en este caso temática, y que puede ejemplificar el «Soneto barroco a la Asunción» $(1939,74)$; hasta el «Epitalamio superrealista a $40^{\circ}$ a la sombra», recuperado por Pérez Corrales, composición que aúna la vanguardia surreal y futurista con rasgos gongorinos $(1981,12)$. Pero también puede rastrearse en la propuesta neopopular de "Invierno" (1928) e incluso en el autorretrato distanciado con forma de homenaje al cinematógrafo llamado «Madrigal sin pretensiones a Greta Garbo. Poema de vía estrecha» (1933). En él se define como «erudito de nómina» y concluye: «eres hoy clamor del que leyó la poesía pura,/ y empaquetó para el reino frío y sin vuelta,/ las páginas llorosas 
de doce años en la selva de las faldas y los cabellos.» Como se verá más abajo, para nuestro poeta, narrador y crítico precisamente la poesía pura es la modalidad lírica de su tiempo que mejor representa la vuelta a Góngora.

\section{Noticias de un centenario actual}

En el año del tercer centenario de la muerte del poeta barroco, Valbuena Prat es catedrático de Lengua y Literatura Espańolas en la Universidad de La Laguna. Por entonces, Dámaso Alonso bosqueja un retrato de familia al hilo del significado de don Luis en la literatura del momento. En dicho retrato, la doble condición poética y erudita de algunos de los conjurados en pro del autor del Polifemo y el surgimiento de una nueva generación de investigadores, como Ángel Valbuena o Gallego Burín, hacen que la recuperación de Góngora se caracterice «tanto como por el entusiasmo, por la seriedad y el conocimiento crítico de la vida y obras de Góngora y de su situación dentro de la literatura de Espańa» (Alonso, 1978, pero publicado en 1932 y escrito en 1927, 766; 1928, 81). No decaerá en Valbuena el reconocimiento a Alonso por la favorable acogida que este dispensó a sus trabajos, una recepción positiva tanto más valiosa porque no fue unánime en el ámbito académico (Valbuena, 1953), y valga como prueba el lugar central y definitorio que le concede en la Historia de la literatura española a la hora de construir su 27 propio y extraño (1968, 687-693) ${ }^{2}$.

Los textos que ese mismo año publica Valbuena en La Rosa de los Vientos arrojan un balance de la actualidad literaria en buena parte coincidente con la «historia oficial» que el crítico contribuirá a ratificar andando el tiempo desde su obra magna citada; claro que, como aquí nos interesan los matices, hay que reparar en las semejanzas y en lo demás. Andando el tiempo, Valbuena declara haber contribuido a los fastos del centenario gongorino en la revista tinerfeña (1974-79, 1306 n.). En mayo de 1927 el joven catedrático, después de expresar algunas reticencias sobre la oportunidad de ciertos aniversarios, hacía constar un deseo: «El centenario de Calderón debiera celebrarse ahora, en que el estilo -barroco, constructivo, deshumanizante- nos acerca al gran simbolista y arquitecto del teatro» (1927 a); pero, ciertamente, si en primera instancia presenta a Pedro Calderón de la Barca, el protagonista de la colaboración termina siendo Luis de Góngora.

2. Todas las citas de la octava edición de la Historia de la literatura española de Valbuena Prat, de 1968, remiten al tomo IV de la misma, salvo referencia expresa a un tomo distinto. 
Una prosa con intensa voluntad de estilo da cuenta de cómo percibe el lector su presente poético:

CENTENARIOS DEL FUEGO.- 1627-1927.GÓNGORA. Un templo barroco, -quizá más rococó- en que arden lámparas votivas de poemas puros, de imágenes diáfanas, de arte deshumanizado. Adornos, dorados, volutas. Los hierofantes que ofician en la gran misa blanca son Gerardo Diego, Lorca, Guillén, Salinas, Alonso, Alberti, Torre. Un momento de poesía análogo al representado por el gongorismo. (...) El nuevo arte, con casi las mismas características señaladas por su teórico Ortega, es el arte de los «cultos». La forma perfecta, la imagen, la separación de toda copia realista (...) Lo mismo ocurre en su dirección hace $[$ sic] una minoría selecta, en su impopularidad. (1927 a).

El relato último que establecerá Valbuena sobre el grupo se encuentra prefigurado en este comentario al calor de los acontecimientos y cuando todavía no se vale del término "generación». La nómina de escritores resulta el elemento más estable de su narración y casi en ese mismo orden, con las salvedades de que Alberti terminará ubicado entre Lorca y Guillén, y de que Guillermo de Torre difuminará su presencia. El concepto central de su definición también comparece en la referencia a «los poemas puros», como ratifica en la reseńa que en ese mismo número de la revista dedica a la edición de las Soledades publicada por D. Alonso (1927 c); mientras que la diferencia que llama más la atención es el evidente protagonismo concedido ahora a Ortega y Gasset y a su ensayo de 1925 La deshumanización del arte. Ambos desaparecen por completo, al menos de forma explícita, en la versión definitiva que Valbuena ofrecerá al respecto.

En la bibliografía del autor, 1927 es también el año de la publicación del segundo tomo de autos sacramentales calderonianos editados por La Lectura. El prólogo confirma desde un registro académico las apreciaciones anteriores: «En el arte en general estamos en el momento de la rehabilitación del barroco. No se explica cómo la vuelta a Góngora en la lírica, no ha traído aún, de un modo pleno, la vuelta (en el teatro) a Calderón» (1927 d, XI); y más abajo explica la razón de ser de su pretensión: "Hoy -siglo $\mathrm{XX}$ - en nombre del arte puro, del nuevo clasicismo y aun del simbolismo -frente al naturalismo-, volvemos todos, consciente o inconscientemente, a Calderón.»(LI). El Valbuena que investiga sobre la Edad de Oro nos parece un historiador bien consciente de la perspectiva presente desde la que lee a los clásicos (cfr. Valdés, 2002, 80; Blanch, 1976, 59). Así que, 
salvando las distancias, barroco vale como arte puro, y romanticismo como humanización ${ }^{3}$, valorándose más lo primero que lo segundo. Cuando de la crónica de la actualidad pasemos a la narración del pasado inmediato, los énfasis serán diferentes.

\section{Un panorama pionero desde 1930}

El primer acercamiento global y con cierto detalle que el crítico realiza a la lírica de su tiempo se llama La poesía española contemporánea y ve la luz en 1930, aunque en los preliminares se señale 1926 como data del grueso de la redacción $(1930,22)$. Tras dedicar sendos capítulos al modernismo, a la generación del 98 y a Juan Ramón Jiménez junto con los novecentistas, el capítulo IV, "Las últimas tendencias», se ocupa de la poesía desde la vanguardia (cfr. A. E. G., 1930; Anderson, 2005, 67-69). Díez de Revenga subraya el carácter de indagación de "primerísima mano" que este libro revela $(2000,95)$. Como sugiere el propio lema del capítulo, apenas una referencia cronológica por toda caracterización, esta es una pesquisa que de entrada adopta una perspectiva de análisis, clasificación y ordenación, y no tanto de valoración por la mera falta de distancia temporal respecto de las obras tratadas $(1930,21)$. Y aun así, un cierto entusiasmo parece innegable en este estudio pionero, entusiasmo compatible con la serenidad crítica a la que siempre aspiró nuestro lector ${ }^{4}$.

El hilo conductor del panorama descrito se sintetiza así: "Toda la poesía actual es "creacionista" en el sentido de la "desrealización", de la "deshumanización” que señaló como típica del arte actual el maestro Ortega y Gasset» $(1930,80)$. A partir de ahí, Valbuena ofrece un análisis de la materia basado en la ubicación geográfica de los autores, planteamiento de raíz

3. El texto de Valbuena tiene especial interés incluso para la historia de la palabra «barroco»: «El barroco es, en cierto modo, arte puro, y el romanticismo la máxima humanización» (1927 d, XII). Alberto Blecua $(2004,152)$ indica que el primero en aplicar el concepto a una época y no sólo a un estilo fue Ludwig Pfandl en su Historia de la Literatura Nacional Española en la Edad de Oro, de 1933, primera edición alemana en 1929. Valbuena supone acaso un precedente, sin duda menos sistemático. De cualquier modo, es claro que perseguir la percepción de Valbuena sobre el barroco supone una empresa distinta de la que ahora nos ocupa.

4. Así a la hora de enfrentarse al teatro de Lope y al de Calderón, advierte: «La crítica serena nos impide sustituir un ídolo por otro; hay que situar en su lugar a cada genio. Caracterizar, no medir» (1927 d, XII). Estamos ante una constante del pensamiento crítico de Valbuena, que se dirige a la escritura de los coetáneos con idéntica actitud: «Aquí nos interesa ante todo caracterizar, no medir» $(1930,88)$. 
positivista que impregna el conjunto de su labor filológica hasta Literatura castellana. Los grupos geográficos y la unidad literaria y que con probabilidad no es el aspecto de su trabajo que mejor ha resistido el paso del tiempo ${ }^{5}$.

Especial interés en relación con La poesía española contemporánea tiene reparar acerca del papel que se otorga en el libro a los rasgos que terminarán por predominar en la visión que Valbuena Prat transmite de su edad. Al resurgimiento gongorino se alude de este modo: «La vuelta a Góngora es uno de los más significativos hechos de la nueva generación. El centenario -1927- es una ofrenda de fervor y hermandad a Góngora de los poetas actuales. Nunca ha coincidido tan bien esta fecha arbitraria con el gusto de una época» (1930, 100). La novedad, andando el tiempo, consistirá en que «uno de los más significativos hechos» se convierta en el más significativo. En todo caso, la presencia del culterano apenas se destaca en esta ocasión, como tampoco la de la "poesía pura» y eso que es una expresión "como un frontón de mármol que reúne a los poetas de este grupo» (109).

Al lado de estas diferencias de énfasis conceptuales, la narración que Valbuena terminará por tramar en torno a sus coetáneos se distingue del relato de actualidad que nos ocupa en que éste carece de final, o más bien no tiene un final verdaderamente construido, como el propio autor apuntaba en su prólogo a modo de captatio benevolentiae (22). En efecto, en un intento de estar al día y poder dar noticia de lo último de lo último, el crítico llega a mencionar textos publicados en revistas y hasta en diarios, a la vez que yuxtapone nombres. Y es que el párrafo final reza: «También debe citarse la abundante floración de poetisas, entre las que recordamos a Josefina de la Torre -fina, depurada, al estilo de Pedro Salinas-, Ernestina de Champourcín, Concha Méndez Cuesta.» (130) La ausencia de una conjunción ante el nombre que remata la serie nos parece sintomática del carácter abierto de un ensayo sin duda arriesgado en su intento de definir el presente (cfr. White, 1992, 31 ss.).

\section{El relato lírico, aspectos formales}

La primera edición de la Historia de la literatura española de Ángel Valbuena Prat sale a la luz en la Barcelona de 1937 y básicamente cuenta un Veintisiete que no alterará la octava edición, de 1968, última publicada

5. 1974-79; cfr. Nuez (1978, 206), Rumeu de Armas (1999) y Díez de Revenga (2000, 90). De forma atenuada respecto del estudio de 1930, volverá a comparecer la geografía en su Historia de la literatura española cuando aborde a los del 27 (v. p. e. 1968, 648; cfr. 1927 b). 
en vida del profesor y a la que nos remitiremos de aquí en adelante ${ }^{6}$. Ello no obsta para que él considerase la obra "como un ser vivo", según destacan María Pilar Palomo y Antonio Prieto $(2000,21)$, quienes además avalan la trascendencia del texto en cuestión al haberse encargado de ponerlo al día y ampliarlo en la novena edición, de 1983. En efecto, estamos ante la empresa de mayor alcance de Valbuena, suma del saber del filólogo y aspecto destacado de la biografía del individuo (Palomo y Prieto, 2000, 17; cfr. Meregalli, 1990, 32), para empezar por cómo se utilizó el libro en el expediente de depuración contra su autor, expediente que le condenará a dejar su Universidad de Barcelona y marchar castigado a la de Murcia en una especie de exilio interior (Serrano Asenjo, 2006).

El primer acercamiento a la narración que nos entrega Valbuena puede dejar un tanto de incertidumbre en el lector. Apenas se tratan cuestiones generales y el discurso se centra más que nada en los grandes creadores. El significado del relato, así, queda deshecho y principalmente sugerido en los títulos de los capítulos, en los epígrafes que los subdividen, en la selección de nombres y en un puñado no muy abundante de referencias sueltas, dispersas aquí y allá. Todo ello corrobora los planteamientos críticos recientes que perciben un evidente componente literario y hasta novelesco en la historiografía (cfr. Jammes, 1987, 130; Pérez Bazo, 2001, XXII; Blesa, 2004, 42).

Vale la pena reparar, pues, en el tipo de narrativa a la que más se aproxima la Historia debatida como paso previo al análisis de cómo queda definido el fenómeno estudiado. White proporciona un punto de partida: «In fact, when many contemporary historians speak of the art of history, they seem to have in mind a conception of art that would admit little more than the nineteenth-century novel as a paradigm» $(1986,42)$. A mi ver, el modelo de la novela decimonónica clásica no termina de funcionar en este caso, mientras que ciertos rasgos de la manera de contar de Valbuena apuntan en otra dirección, en rigor una derivación de aquélla, la representada por la novela lírica, que alcanza su momento de mayor auge en el primer tercio del siglo XX.

6. Al menos en este tramo de su Historia, Valbuena procede sobre todo por acumulación. El cotejo de las ediciones primera y octava no ofrece muchos cambios en el texto inicial y sí la comprobación de ańadidos. Esto sucede principalmente en el segundo de los dos capítulos dedicados al tema que nos ocupa: LXXII y LXXIII, en 1937; LXXVII y LXXVIII, en 1968. La forma de proceder indicada crea algunos desajustes puntuales en el texto definitivo, valga el siguiente ejemplo. Al tratar la figura de Guillén, en 1968 leemos algo que si valía para edición primera, no se tenía después: «La última lección de Cántico (1936) recoge las últimas formas, la dirección definitiva del maestro» $(1968,670)$. 
Aspectos del relato como lo fragmentario ya señalado, con lo que ello supone de necesidad de una clase de lector activo, imprescindible en su recreación, copartícipe y cómplice (cfr. Gullón, 1984, 45); o la utilización del lenguaje poético y un tipo de escritura unánimemente considerada por los investigadores como "personal» (Romero Tobar, 1999, 37; Pozuelo Yvancos, 2000, 60) resultan rasgos que comunican la Historia de la literatura española con la novela de su tiempo, la que encarnan Miguel de Unamuno, Gabriel Miró o Ramón Gómez de la Serna, pero también André Gide o Virginia Woolf. No estará de más ahora recordar la observación de Perkins sobre cómo el historiador literario conforma su punto de vista desde el mundo en que vive $(1992,14)$. Y el mundo en que vive Ángel Valbuena obviamente está compuesto tanto por factores de época, v. gr. los códigos literarios contemporáneos recién aludidos, a los que no podía ser ajeno alguien bien informado como él; como por las circunstancias más personales. Por fecha de nacimiento, por formación y sensibilidad, el historiador, al igual que Ángel del Río, es uno de ellos, «Él se consideraba del 27» (Palomo y Prieto, 2000, 22). Así que los capítulos LXXVII y LXXVIII de la obra glosada en buena ley han de ser considerados como un tramo nada menor de la autobiografía de su autor; en otras palabras, como sucede en la novela lírica (Gullón, 1984, 27), el escritor se convierte aquí en materia misma de la narración. Algo no tan distinto de lo que sucedió en Teófilo.

Y si la construcción la hace el yo y la sustancia es de carácter personal, «en consecuencia, la creación es subjetiva y al expresar algo eminentemente propio, tiende al lirismo» (Gullón, 1984, 44). En nuestro caso abundan las muestras de ese tenor. Como cuando se explora la poesía de Jorge Guillén, sin lugar a dudas el nombre que quintaesencia lo que significa la cifra de 1927, al menos en el campo de la pura creación: «Belleza intelectual que al revalorizar todas las cosas vitales ha de llegarnos por medio del pensamiento. Idea, alma del poema que al arrancar en el cuerpo marfileńo de la forma ilumina, como un grito, el paisaje interior que ante nosotros se abre» (1968, 671). O cuando más abajo se presenta la labor de Josefina de la Torre en un lenguaje que literalmente recrea en prosa poética los versos de la artista canaria: «Musa niña, jugaba con el aire, con la arena fina de la playa, con los luceros de la noche. Una humedad de pies de cristal, descalzos, ha penetrado en ese mundo en sonrisa, de fiesta de visión, de deporte de latidos, de escondite de agilidad" (708).

En todo esto, Valbuena Prat, como buen hijo de su época, procede a sabiendas, vale decir, con voluntad y conciencia de estilo. La mejor prueba de ello se encuentra en su lectura de la tarea erudita de un buen colega como Dámaso Alonso. En efecto, La poesía de San Juan de la Cruz es valorada así: 
«posee atisbos y análisis seguros, y páginas de tersa belleza. Hoy suponen un momento capital en la historia de la crítica literaria, como obra de belleza creadora, sus Ensayos sobre poesía española» (1968, 691; cfr. Meléndez, $1930,15)$. La sensibilidad y la inteligencia unidas constituyen la base de la operación de leer, con su escritura subsiguiente, tal como la discierne el autor en un modelo de excepción ${ }^{7}$. De igual modo intenta actuar por su lado, aunando el rigor con la estética. A continuación atendemos a la empresa a cuyo servicio se ponen dichos instrumentos.

\section{El Veintisiete según Ángel Valbuena}

En principio, la explicación dada al nombre con el que se encabezan los capítulos LXXVII y siguiente de la Historia de la literatura española, a saber: "La generación de 1927: La poesía pura: Diego, Lorca, Alberti, Guillén, Salinas» y «La generación del 27: Humanismo, poesía, teatro y prosa» (1968, 639 y 687), no aclara demasiado: «Hemos escogido el nombre de "generación del 1927”, por creerlo el más significativo, para las importantes figuras que nacen en torno al 1900. El centenario de Góngora, la revalorización del poeta barroco, y la participación de todos los poetas e importantes prosistas en esa fecha llevan un "supuesto" de grupo y de actitud" (639) ${ }^{8}$. Llama la atención menos que la fecha de 1900 sea el año de nacimiento del autor, y más que no se incluya en ese momento inicial de la exposición comentario alguno sobre el significado del ingenio barroco. Hay que ir más adelante para encontrar como al paso alguna luz sobre un particular tan relevante, a la vez que tan flagrantemente obviado.

La hallamos en el tratamiento de la obra de Alberti. Y es que el de Cal y canto y sus compañeros homenajean a don Luis, "con el que se sentían compenetrados en el culto del arte puro, en la técnica trabajada, en la seriedad de un arte difícil, para minorías» $(1968,663)$. Junto a ciertas resonancias orteguianas, pero sin nombrar a Ortega entonces, Valbuena apunta en la

7. Tiene interés aportar un pasaje más al respecto igualmente referido a Alonso: «A través de la obra crítica de Dámaso, actúan, por lo tanto, a la vez el poeta y el filólogo y analizador. Del predominio del primero puede surgir el tipo entusiasta de ensayo, en el que todo es afirmación o delectación de artista; del exceso de criticismo puede llegarse al pormenor puramente analizante, incluso escéptico respecto al resultado. De la síntesis de ambos valores, la unión de comprensión y crítica, en páginas de auténtica expresión apasionada de belleza.» $(1968,692-693)$.

8. Un marco reciente para situar la cuestión en el capítulo 5 «¿La ficción del 27 o Generación del 27 S. A.?» de Mateo Gambarte (1996, 165 ss.); y con mayor ecuanimidad García de la Concha $(1998,23)$ y Soria Olmedo $(2004,71)$. 
cita la trascendencia que concede a las continuaciones de los títulos de sus dos capítulos de referencia, es decir, el Veintisiete tiene dos caras, es poesía pura y también humanismo. Y el campeón de la pureza para el historiador es Jorge Guillén, al margen de que éste en la conocida carta a Fernando Vela incluida en la antología de Gerardo Diego expusiese que lo suyo más bien era una poesía compuesta, en definitiva, una " "poesía bastante pura", ma non troppo» (1991, 404).

Nuestra obra presenta a Guillén como "el clásico de la poesía nueva» (1968, 669), que además culmina lo que significa la pureza en Cántico. Sin duda es de lamentar que el crítico no mencione ningún componente ulterior de lo que será Aire nuestro, pero lo cierto es que el Guillén de Valbuena es el del primer libro, independientemente de que este título, a diferencia por ejemplo de Sobre los ángeles, no se destaque en los epígrafes que recogen la información sobre el vallisoletano: «La poesía intelectual de J. G.» y «La ciudad, el paisaje castellano, el aire en la poesía de G.». Pues bien, el juicio que merece su producción resulta rotundo: «Difícilmente puede encontrarse, en cualquier literatura, un libro de una unidad esencial y de un intenso contenido de constante creación lírica, tan exquisito y tan perfecto como Cántico» (671). Y la comparación con el poeta de la Edad de Oro se produce al poco: «Guillén, diverso y afín a Góngora, es un ejemplo a la vez de poeta claro y difícil. Si logramos intuir la belleza de su lírica -como en el caso de Las soledades- un mundo inmenso se iluminará ante nuestros ojos, deslumbrados de hermosura y vida» (671) ${ }^{9}$. Asunto distinto es que justamente el texto gongorino mencionado haya merecido con anterioridad un juicio negativo en la Historia de Valbuena Prat, juicio en el que importará sobremanera la dificultad, que impone una recepción restringida a unos pocos. Al cabo, son la oscuridad y sus bases formales de rigor y disciplina los componentes más subrayados de esa pureza, por encima de otras señas también apuntadas como el equilibrio o el orden (cfr. 663 y 737 s.).

Ahora bien, como ya se dijo, estamos ante un fenómeno con dos perfiles, no del todo bien avenidos. "La generación del 27 no es sólo "poesía pura". Precisamente, el gran revalorizador de Góngora [D. Alonso], además de ser el humanista de este grupo, penetra en su última poesía en mundos

9. Ambos pasajes muestran dos leitmotiven de largo recorrido en la construcción crítica de Ángel Valbuena, se trata de esencia / esencial y de intuición / intuir. No cabe aquí abordar este asunto con el espacio debido, pero quizá pueda relacionarse con la presencia en la obra de Arthur Schopenhauer, sin duda uno de los filósofos más citados del libro. Cfr. Schopenhauer (1960, II, 241, 259 ó 273) y sobre el arte como conocimiento esencial en el filósofo alemán, v. Maceiras Fafián (1985, 74 ss.). 
íntimos, humanísimos, que rozan el panorama existencial, y la adivinación superrealista del subconsciente.» $(1968,687)$. La fecha mágica, por un lado, significa hacer de don Luis un «artífice de hoy» (674), de forma que Guillén, o Alberti, o Salinas, recrean a la manera moderna la poética del culterano; pero, para Valbuena, por otro lado, también supone realizar una lectura filológica del modelo ubicándolo con todo respeto histórico ${ }^{10}$ como un artífice de ayer. Ahí encaja sobre todos Dámaso Alonso, «el mejor aglutinante de la generación» (693).

La vuelta a Góngora consiste en su gran logro como investigador, sólo que Alonso es profesor y, además, poeta. Ángel Valbuena Prat se vale en su interpretación de los acontecimientos historiados de dos términos tan próximos para él como humanista y humano, con el citado superlativo como recurso enfatizador, términos que remiten a ambas actividades de su colega, todo a fin de establecer su lectura personal del pasado. Alonso puede, de entrada, mirar a Góngora con «ojos de artista puro» $(1968,688)$, mas las cosas literarias cambian y la dirección en que se mueven pasa por lo existencial y lo íntimo de la mano más o menos explícita o declarada del surrealismo, siempre desde la perspectiva de nuestro lector, tan privilegiado como parcial. A mi ver, de este modo el crítico en realidad plantea una toma de posición. El Góngora hegemónico de un momento dado le resulta menos humano, pero no se puede separar en sentido estricto de la labor humanística que lo descubre. El pasado proporciona figuras para definir el presente, lo que ocurre es que el presente que importa al historiador es más humano.

Lo confirmaremos con el análisis de La destrucción o el amor: "Después de la muerte", "Sin luz", "Corazón en suspenso" son ya títulos que revelan una nueva actitud humanizada, hondamente humanizada de terror, misterio o tinieblas al lado de los juegos intrascendentes en que empezó la labor de artistas de la generación de Aleixandre» $(1968,698)$. En gran medida, el quid de la cuestión yace en que a esas alturas, ańos treinta, se discierne un cambio de modelo. El mismo año 1933 en que La destrucción o el amor recibe el Premio Nacional de Literatura coincide la publicación de Garcilaso, de Manuel Altolaguirre, y el comentario del crítico, sin ser del todo explícito, parece lo bastante claro:

10. Tal es la definición que Valbuena, a nuestro modo de ver, concede al término humanista en este contexto, es decir, una traslación en gran medida metafórica desde la acepción más técnica del vocablo como persona que en el Renacimiento era versada en las humanidades, en especial las lenguas y cultura grecolatinas. Como parece lógico, en lo que sigue nos ceñimos al uso particular que el crítico hace de la palabra. 
Fruto de esa visión humanizada es su Garcilaso -biografía que sólo nos interesa aquí como obra de poeta-, en quien ve, personalmente, un traslado de su propia inquietud romántica -en él, el elegante renacentista de ninfas de cristal-, que puede ser todo un símbolo, frente al Góngora del centenario, del cambio de rumbo en la actual lírica (701).

Vale decir, el caballero del Emperador significa la «visión humanizada», ante un Luis de Góngora que necesariamente ha de ser emblema de algo diferente que no se nombra, pero que en el contexto de que hablamos únicamente puede ser deshumanización.

\section{Las tensiones de una historia autobiográfica tachada}

La tensión primigenia que late en la historia o narración examinada consiste en que la aceptación de la fórmula «generación del 27» remite en exclusiva a un momento muy temprano de la producción de sus presuntos miembros y este hecho se ve reforzado por otra opción de Valbuena Prat en la misma línea, a saber, los títulos de libros poéticos destacados en sus epígrafes: Ángeles de Compostela, de 1940, Romancero gitano, de 1928, y Sobre los ángeles, de 1929 (1968, 645, 652 y 664 respectivamente; cfr. Mateo Gambarte, 1996, 282-3). La elección de estas obras en cierto modo congela el retrato de sus autores, a pesar de que algunos de ellos, con la excepción de García Lorca, siguen escribiendo unas cuantas décadas más y a finales de los años sesenta estaban en activo. Pero es que, además, como se señalaba arriba, el representante más acreditado de la pureza según el propio historiador establece, Cántico, no cobra el protagonismo organizativo y tipográfico de los precedentes títulos, que no se ubican precisamente en el campo acotado por la expresión "poesía pura».

Sin embargo, la raíz esencial del conflicto que late tras dichos desajustes hay que buscarla en el significado del mismo Luis de Góngora, que no se halla principalmente en el capítulo acerca de sus seguidores modernos, sino en el suyo propio, como corresponde. Evidentemente la interpretación que de él sugiere Ângel Valbuena está muy unida al novecientos: «se explica que en un momento de elevación de la poesía minoritaria y aristocrática, haya surgido en la cumbre del Góngora del centenario (1927), el ejemplo de las Soledades para el entusiasmo de un culto, para el comentario, para la modernizada imitación» (1968, II, 262). Esto nos lleva a concentrar la mirada no tanto en el conjunto de la creación del autor, sino en sus interrumpidas Soledades. No le faltaba razón a Valbuena cuando aseguraba que la batalla en torno a 
este texto polémico seguía viva por entonces (1968, II, 244). Así que, con impecable coherencia, él participa en la refriega:

Las Soledades son más un fracaso que una culminación. La poesía «críptica» es esencialmente falsa. (...) ¿Cabe en una poesía, por bellezas que contenga, tener que ser traducida en prosa, en su misma lengua? ¿En qué gran poema ha ocurrido esto? Respetamos sus bellezas, y las saboreamos; pero nuestro juicio es, en definitiva, negativo. (1968, II, 263).

De donde podemos deducir que el Veintisiete de Valbuena es mucho menos el de la imitación moderna que el del comentario gongorino, menos el de la poesía pura que el del humanismo tal como él lo entiende y percibe en un Dámaso Alonso. Y además 1927 no sólo es el año de la vuelta a Góngora, sino también y sobre todo, por lo que respecta a nuestro filólogo poeta, el ańo de su llamada a recuperar a Pedro Calderón de la Barca.

En efecto, en las páginas de la Historia de la literatura española dedicadas al de Los encantos de la culpa se dice: "Cuando en 1927 lancé el grito de la "vuelta a Calderón", estaba ya el ambiente favorable. Lo que entonces era su anuncio es hoy una realización.» (1968, II, 616). Y sigue la reseńa de una considerable cantidad de lazos que unen la estética calderoniana con la del siglo XX, el perfeccionismo, el teatro de ideas, la mezcla de ironía y seriedad, y "su sistema, su arquitectura, su compleja y completa trabazón ideológica» (1968, II, 616-617). Si a todo ello sumamos la valoración global que de él ofrece Valbuena como la figura más significativa de las letras del XVII por su talante reflexivo, simbólico, "creador de un mundo alado y subjetivo"; mientras que Góngora apenas si es recordado por su carga decorativa ${ }^{11}$, todavía más ha de llamar la atención que cuando aborde el fenómeno de la «generación del 27», fecha para Valbuena tan gongorina como calderoniana según acabamos de ver, las referencias al madrileño apenas si queden en alusiones contadas y marginales ${ }^{12}$.

11. Merece la pena tomar nota del pasaje íntegro: «Calderón es la figura más significativa de la poesía del seiscientos. Con el elemento decorativo de Góngora, las esencias del teatro nacional de Lope y la significación teológico-casuista, Calderón, reflexivo, sistemático, simbólico, creador de un mundo alado y subjetivo, es a la vez la época y lo universal» (1968, II, 525).

12. Valgan un par de muestras, además de la inevitable alusión a La hija del aire para explicar el prodigioso Yo era un tonto y lo que he visto me ha hecho dos tontos $(1968,664)$. Así sobre Guillén, se lee: «En función del amor, los tallos, la soledad que se hace ligera, "balcones", "bosques, aves, aires" -que en los finales de parlamentos calderonianos también cobraban nueva significación, como acompañantes de un solo patetismo-, aquí, en la cotidiana sencillez de la belleza guilleniana, son otros» (672); o sobre Miguel Hernández: 
La presencia menor de Calderón aún puede ser rastreada, en cambio a José Ortega y Gasset no se le cita en absoluto a la hora de explicar el fenómeno que nos atañe. Y eso que La deshumanización del arte expone el sentido del arte puro, lo define y lo sistematiza. Ahora bien, estamos ante un ensayo con el que Valbuena Prat discrepa rotundamente: «nos parece inflada la cálida adhesión que se respira hacia lo "nuevo", no precisamente por ser nuevo, sino por cimentarlo en lo más efímero de él, en lo "antihumano". Cuando una forma de arte nuevo se logra, es lo de menos que sea deshumanizado o no» (1968, III, 574). El polémico texto orteguiano es sintetizado por el estudioso de Calderón como una "filosofía de la moda», algo, por ende, de poco interés y hasta negativo para alguien que sostuvo que "todo gran arte es trascendente, ya por proponérselo, ya por derivarlo de su misma compleja fecundidad» $(1968 \text {, III, 574) })^{13}$.

De cualquier forma, en el discurso analizado hay una ausencia todavía más clamorosa que la de Ortega y es la de Ángel Valbuena Prat, i. e., la del $y o$, o si se prefiere, la de marcas de la primera persona gramatical. De inmediato hay que precisar que algunas pruebas en contra de lo anterior podrían exhibirse, pero repárese en que suele tratarse de un yo lector-crítico que opina desde fuera sobre tal o cual pasaje objeto de comentario, como cuando en un alarde interdisciplinar muy sugerente indica que los ángeles de Alberti: «A mí me recuerdan también los ángeles románicos del Museo de Arte de Barcelona» (1968, 665); o a cuenta del espacio urbano en Guillén anota que «la ciudad vaga de tinieblas y bicicletas, me hace el efecto de que no puede ser más que inglesa -Oxford o Cambridge» (676). Sólo encuentro un momento en que el nivel de compromiso explícito del sujeto con su materia va más allá de la mencionada actitud, y es al abordar la producción de José María Pemán: «Nuestra generación, influida del excesivo rigor de la poesía pura, fue injusta -fuimos- con esta obra y otras análogas» (722). Es solidario con todo lo advertido hasta aquí que en la única ocasión en que vincula su trayectoria personal con la poesía pura, Valbuena reconozca un error.

Sin embargo, resulta obvio que una valoración justa del alcance de esta ausencia sólo puede realizarse a partir de documentos que acrediten el significado de la presencia tachada. Al menos tres textos del Valbuena maduro

«Sus octavas y sonetos reúnen gongorismo a lo 27 , neogarcilasismo, y hasta calderonismo formal (fue muy aficionado a revalorizar y escribir en el género del "auto sacramental")» (703).

13. Al poco rubrica su postura al aludir al «callejón sin salida del arte deshumanizado de la moda» (1968, III, 575). Cfr. Urrutia (2006). 
se acercan, además de la Historia de la literatura española, al Veintisiete, con la particularidad de que todos ellos proponen versiones de los hechos con una dimensión autobiográfica relevante. En 1953, publica un artículo a modo de balance en los veinticinco años del grupo. Tras un párrafo introductorio, el marco de regreso al XVII propicia la mezcla de autorreivindicación y ajuste de cuentas: «Nuestra vuelta a Calderón también se definió en 1927 como tendencia paralela a la rehabilitación del lírico barroco, y aunque recibida con alguna salvedad por los fríos investigadores del Centro de Estudios Históricos, tuvo, allí mismo, la cálida aceptación, como era natural, por el poeta y gongorista D. Alonso» (1953). Y en seguida, recuerda otro par de modelos para «nuestra generación» como Quevedo y Gracián.

Así que no extrañará que la primera de las revistas de las que se dice que homenajearon a Góngora sea La Rosa de los Vientos, por más que, en este caso, Ángel Valbuena no se retrate junto a ella, a pesar del peso que tuvieron sus colaboraciones al respecto y que ya citamos arriba. Y como el crítico además es creador: «También el que esto escribe compuso un "Eco y Narciso", entre gongorino y cubista, que nos hace una cierta gracia, no desprovista de simpatía, al cabo de sus veinticinco ańos» (1953). Pero el profesor se impone al poeta, no vuelve a repetirse la confidencia y ratifica la trama principal sobre el tema tratado que pasa a la Historia, con una diferencia de matiz que nos ayuda a entender más claramente su obra mayor:

Precisamente ese término de "poesía pura", que también definió a esta generación, la hacía coincidir con la acerada frialdad aparente del marmóreo sonetista de Córdoba y con la poesía intelectual francesa del maestro Paul Valéry. En el fondo venía a apoyar, de momento, la teoría de una moda de «deshumanización del arte», de Ortega y Gasset, que acogió en su Revista a los celebrantes del culto, aunque hizo advertencias sobre nuestro barroco, que como otras referentes a Calderón, en un libro reciente, no demuestran precisamente comprensión. (1953).

De manera que la «deshumanización» no sólo es filosofía de la moda, sino moda ella misma y, por lo tanto, algo pasajero como sugiere el paréntesis «de momento». Al fondo, se discierne una disparidad total de planteamiento con Ortega que involucra a la que Valbuena considera como su gran aportación a la cultura española coetánea, la recuperación de Calderón de la Barca. A mi ver, el rechazo de determinadas reflexiones orteguianas va tan allá, que en la Historia de la literatura española el autor opta, como vimos, por eludir 
cualquier referencia directa al contar su versión del movimiento en el que él se integra ${ }^{14}$.

En La literatura española en sus relaciones con la universal, de 1965, el tono beligerante se hace más afilado y Valbuena Prat rememora su labor novelística. Al principio, incluso da la sensación de dudar del concepto debatido: "la llamada "generación del 27", de la "literatura pura" o lo que definió Ortega como "la deshumanización del arte" (1965, 519). Pero lo que sigue no admite reservas sobre una toma de postura que rebasa lo meramente teórico y afecta también a la práctica misma de la creación literaria: «el que esto escribe nada tiene que ver con tales prejuicios. Sus novelas son todo lo contrario a la "deshumanización”"(ibid.). Algo después queda definitivamente establecida la carga personal que está en juego en torno a estas aparentes disquisiciones académicas: "Hoy, De Nora ha revalorizado mis novelas (...) su trascendencia o su "humanidad" hasta el máximo son lo que creo superó una moda aséptica y antinarrativa (...) y no los grupos orteguistas de "Nova novorum", que un contemporáneo, en latín macarrónico, llamaba "pelma pelmorum" " (ibid.). No justificaría la acidez del ataque una mera diferencia sobre la mayor o menor trascendencia del hecho artístico, sino acaso lo que de negación de lo más propio el crítico percibe en los denostados «Nova novorum» y su contexto doctrinal. Negación de lo propio social, frente a su «neocalderonismo» Valbuena sitúa la «deshumanización»; y de lo propio intimo expuesto a través de las ficciones Teófilo y $2+4$. Es obvio que, desde el punto de vista de don Ángel, ni sus obras de creación, ni sus aportaciones en torno a Calderón habían sido justamente consideradas, con las pocas excepciones que subraya.

Sea como fuere, desde la última vuelta del camino que supone Literatura castellana. Los grupos geográficos y la unidad literaria, cuyo segundo volumen sale a la luz póstumamente, el yo que apunta levemente aquí y allá, sin abandonar en absoluto las reticencias veintisietistas ${ }^{15}$, más que nada es un

14. En todo caso, el pronunciamiento más duro de Valbuena hacia Ortega, al menos en las páginas de la Historia, resulta de una comparación con don Ramón Menéndez Pidal: «A diferencia de ciertos aspectos de Ortega Gasset [sic], Menéndez Pidal no es el desdeńoso ni el negativo, sino el gran comprensor de toda la gran cultura española. Su palabra es siempre justa y medida; su entusiasmo, pasión de inteligencia; su continuo estímulo, la mejor justificación de los temas. Menéndez Pidal abre el novecentismo de nuestra crítica científica y filológica sin la actitud agria del escéptico ni la suficiencia arrogante del osado» (1968, III, 599).

15. Así «en España el nombre de "generación del 27” agrupa la época de la que se llamó "poesía pura”, cuyos nombres capitales son Guillén, Salinas, Dámaso Alonso, Lorca y Alberti (algunos como Federico, bien poco propios en su obra de la "pureza" abstracta o intelectual, o renegadores del término como Dámaso en su época madura)» (1974-79, 1291). 
yo elegíaco. El recuerdo del mexicano Jaime Torres Bodet (1902-1974) y su novela Proserpina rescatada propicia lo confesional: «Sigo la ed. de EspasaCalpe, amablemente dedicado el ejemplar por el autor, recuerdo a la vez grato y doliente, ya que durante la redacción de este estudio me entero de la muerte del notable poeta, narrador, diplomático y humanista tan vinculado a nuestro "27"”(1974-79, 1305 n.). Y a modo de epifonema sentencia: "iY a cuántos maestros, compañeros, amigos y escritores se ha llevado a su misterio la verdadera Proserpina!» (ibid.).

El espacio en tipo menor de las notas al pie recoge los pasajes de mayor intensidad de la memoria, volviendo sobre los nudos centrales de su discurso con variaciones siempre significativas: «El que esto escribe contribuyó a la "gloria" del centenario gongorino en la revista La Rosa de los Vientos, de La Laguna, Tenerife, en cuya Universidad estrenaba su labor de catedrático en España, acabada en Madrid, a los cuarenta y cinco años de escalafón» (197479, 1306-1307 n.). El salto, en apariencia un tanto extravagante, desde la revista de juventud a la dilatada trayectoria profesional, ya concluida, insiste en la importancia que tiene para el sujeto nuestro objeto de estudio. A la postre, la cifra de 1927, valga por lo que valga, es carne y sangre de la historia de vida de Ángel Valbuena Prat. Y una consideración más, entre las últimas palabras que dejó escritas al respecto se cuentan las siguientes: «Jorge Luis Borges nace en 1899. Por la fecha, coincide con la llamada, en España, "generación del 27" (él y yo, aparte Alberti, que vio la luz en 1903 [sic], somos los de menos años, aunque con pequeña diferencia)»(1974-79, 1313, cursiva mía). Es decir, el autor compatibiliza de continuo las vacilaciones sobre el famoso marbete con el hecho de incluirse en su nómina.

\section{Una salida pactada}

Sin duda, historiar el pasado depende de la experiencia del presente (Beltrán, 2004, 327; y 2005) y todo se complica cuando quien elabora el relato no sólo fue testigo de los acontecimientos, sino actor además (cfr. Chabás, 2001, CXIII; Blesa, 2004, 32). La Historia de la literatura española junto al resto de la crítica de Valbuena Prat en lo que atañe al Veintisiete nos pone ante esta situación con un añadido vidrioso: don Ángel fue un actor hasta cierto punto vencido, o al menos postergado ${ }^{16}$. En último

16. Todavía puede darse una circunstancia mediadora más en la construcción del relato histórico, se trata de que dicho relato se vincule estrechamente con la suerte vital del historiador. No se olvide el papel destacado que ciertos pasajes de la Historia de la literatura española de Valbuena juegan en la instrucción de su expediente depurador; pues bien, sólo 
término, parece que el escritor presenta una narración en la que tan sólo cree a medias. Góngora, juzgado un tanto negativamente per se, llena el primer plano a la hora de dar cuenta del hoy; mientras que Calderón, cuya actualidad es reclamada sin ambages, desaparece casi totalmente a la hora de explicar el tiempo del historiador. Un Calderón que significa, no se pierda de vista, el eje primero en torno al que discurre el currículum profesional y vital de Ángel Valbuena, desde su tesis doctoral o aquellas ficciones líricointelectuales de juventud.

La «deshumanización del arte» no comparece al dar cuenta del 27 y sí lo hace el factor humano en el segundo capítulo que discurre acerca de la "generación». Romero Tobar señalaba recientemente que en las historias de la literatura el argumento de la obra se dirige siempre hacia un fin determinado (2004 a, 79). Pues bien, el de los textos que nos ocupan en estas páginas, en rigor, parte de la tarea humanista que en los años veinte relee filológicamente a algunos barrocos ilustres y camina hacia la trascendencia pretendida por Valbuena en las grandes cimas de arte, y lo hace de la mano del hombre. Así percibe la trayectoria de los suyos en Literatura castellana:

el tono revolucionario con que empezó parte del grupo se sustituye por una serena perfección en cierto modo clásica. A la tendencia de la "poesía pura» se integra un amplio concepto humano. Puede decirse que su punto de partida más o menos gongorino supone una exigencia formal, que se llena cada vez más de profundo calor humano. (1974-79, 1349).

La moraleja de la historia que reúnen la exigencia formal y lo humano deja a salvo los valores propios del historiador ${ }^{17}$. Mas el análisis aquí realizado aporta quizá alguna advertencia ańadida. Este discurso sobre la obra y la existencia del mismo crítico es bien complejo y, en más de un sentido,

como mecanismo de autodefensa ante esa situación límite puede entenderse una observación como la siguiente, que hoy nadie suscribiría: «En la generación de la poesía pura el sentido católico predomina, cualquiera que sea la evolución personal de cada lírico» (1940, 178; cfr. Serrano Asenjo, 2006). Quizá en esta circunstancia extrema deba entenderse el subrayado de Ángeles de Compostela (1940) como la obra más significativa de Gerardo Diego (1968, 645).

17. Perkins, 1992, 168; cfr. White, 1992, 29. Tiene interés recordar en este final unas palabras de Marshall Brown que bien pueden aplicarse a nuestro caso: «histories sensitive to swerve and nuance -the kind of history that a less-than-heroic individual can write, the kind of history responsive to the temporality de Man found in literature-can recover the marks of expression before they congeal, for better or worse, into configured signs of the times» (2002, 143). 
traumático. Sus tensiones o inquietudes, que dejan ver sobre todo algunos vacíos y unas cuantas reticencias y casi desmentidos, ratifica con dureza el riesgo de hacer historia contemporánea, esto es, construcción intelectual de la vida propia, con los pactos y renuncias consustanciales a empresa tan quijotesca. De cualquier modo, hay que hacer constar que la dimensión autobiográfica de los textos estudiados parece inevitablemente atada a la elaboración histórica o crítica, quedando, al cabo, el yo y sus avatares como el hilo conductor que confiere significado a la expresiva máscara calderoniana y a la ajena máscara gongorina.

\section{Referencias bibliográficas}

A. E. G., «La poesía española contemporánea», La Gaceta Literaria, 96, 15-121930, p. 12.

Alonso, Dámaso, "Calderón de la Barca.- Autos sacramentales», Revista de Filología Española, 15, 1928, p. 79-81.

- «Góngora y la literatura contemporánea» (1932), en Obras completas. V. Góngora y el gongorismo, Madrid, Gredos, 1978, p. 725-770.

Anderson, Andrew A., El Veintisiete en tela de juicio. Examen de la historiografía generacional y replanteamiento de la vanguardia histórica española, Madrid, Gredos, 2005.

Beltrán Almería, Luis, "Los límites del nuevo historicismo», en Isaías Lerner, Robert Nival y Alejandro Alonso (eds.), Actas del XIV Congreso de la Asociación Internacional de Hispanistas, 1, Newark, Juan de la Cuesta, 2004, p. 325-334.

- «New Historicism and Hispanism», en Luis Fernández Cifuentes and Brad Epps (eds.), Spain Beyond Spain. Modernity, Literary History, and National Identity, Lewisburg, Bucknell UP, 2005, p. 270-281.

Blanch, Antonio, La poesía pura española. Conexiones con la cultura francesa. Madrid, Gredos, 1976.

Blecua, Alberto, «El concepto de Siglo de Oro», en L. Romero Tobar (ed.), 2004, p. 115-160.

Blesa, Túa, «Leyendo en las historias géneros y estilos», en L. Romero Tobar (ed.), 2004, p. 31-43.

Bonet, Juan Manuel, Diccionario de las vanguardias en España 1907-1936, Madrid, Alianza, 1995.

Brown, Marshall, «Rethinking the Scale of Literary History», en L. Hutcheon y M. J. Valdés (eds.), 2002, p. 116-154.

Chabás, Juan, Literatura española contemporánea 1898-1950, ed. Javier Pérez Bazo, con la colaboración de Carmen Valcárcel, Madrid, Verbum, 2001. 
Díez de Revenga, Francisco Javier, «Recuerdo bibliográfico de Ángel Valbuena Prat», Monteagudo, 57, 1977, p. 39-45.

- «Valbuena Prat y los poetas de su generación», Monteagudo, 5, 2000, p. 83-95.

Espinosa, Agustín, "Ángel Valbuena Prat. 2 + 4», La Rosa de los Vientos, 1, abril 1927, p. 17-18.

Ferrater Mora, José, Diccionario de Filosofía, 2, Madrid, Alianza, 1979.

García de la Concha, Víctor, «Introducción», en AA. VV., Poetas del 27. Antología comentada, Madrid, Espasa-Calpe, 1998, p. 21-84.

Guillén, Jorge, «Poética. Carta a Fernando Vela», en Gerardo Diego (ed.), Poesía española contemporánea, ed. Andrés Soria Olmedo, Madrid, Taurus, 1991, p. 403-404.

Gullón, Ricardo, La novela lírica, Madrid, Cátedra, 1984.

Hutcheon, Linda, «Rethinking the National Model», en L. Hutcheon y M. J. Valdés (eds.), 2002, p. 3-49.

- y Mario J. Valdés (eds.), Rethinking Literary History. A Dialogue on Theory, New York, Oxford UP, 2002.

Jammes, Robert, "Apuntes sobre Literatura española contemporánea 1898-1950 de Juan Chabás», en Javier Pérez Bazo (ed.), Homenaje a Juan Chabás. Dianium, Denia, Centro Asociado UNED, 1987, p. 127-136.

Maceiras Fafián, Manuel, Schopenhauer y Kierkegaard: Sentimiento y pasión, Madrid, Cincel, 1985.

Mateo Gambarte, Eduardo, El concepto de generación literaria, Madrid, Síntesis, 1996.

Meléndez, Concha, «Un escritor novecentista: Ángel Valbuena Prat», en Á. Valbuena Prat, 1930, p. 9-15.

Meregalli, Franco, "Panorama de las historias de la literatura española», en AA. VV., Historia de la literatura española. Desde los orígenes al siglo XVII, 1, Madrid, Cátedra, 1990, p. 25-34.

Nora, Eugenio G. de, La novela española contemporánea (1927-1939), Madrid, Gredos, $1973^{2}$.

Nuez, Sebastián de la, "Ángel Valbuena Prat iniciador de la crítica y la historiografía modernas en la poesía canaria», Revista de Historia Canaria, 171, 1978, p. 203218.

Palomo, María del Pilar y Antonio Prieto, «Historia de una Historia», Monteagudo, 5, 2000, p. 13-27.

Perkins, David, Is Literary History Possible?, Baltimore and London, The Johns Hopkins UP, 1992.

Pérez Bazo, Javier, «Estudio preliminar», en J. Chabás, 2001, p. XIX-LXXX. 
Pérez Corrales, Miguel, «Un poema de Ángel Valbuena a Agustín Espinosa», Jornada Literaria, 24-1-1981, p. 11-12.

Pozuelo Yvancos, José María, «Ángel Valbuena: La renovación de la historiografía literaria española», Monteagudo, 5, 2000, p. 51-69.

Río, Ángel del, Historia de la literatura española. Desde 1700 hasta nuestros días, $1^{\text {a }}$ ed. 1948, Barcelona, Bruguera, 1982.

Romero Tobar, Leonardo, «Entre 1898 y 1998: La historiografía de la literatura espańola», Rilce, 15.1, 1999, p. 27-49.

- (ed.), Historia literaria / Historia de la literatura, Zaragoza, Prensas Universitarias, 2004.

- «La historia literaria, toda problemas», en L. Romero Tobar (ed.), 2004 a, p. 67-85.

Rumeu de Armas, Antonio, "Valbuena Prat y la poesía canaria», El Día, 1-8-1999.

Santiánez Tió, Nil, «Temporalidad y discurso histórico. Propuesta de una renovación metodológica de la historia de la literatura española moderna», Hispanic Review, 65, 1997, p. 267-290.

Schopenhauer, Arturo, El mundo como voluntad y representación, 2, trad. Eduardo Ovejero y Mauri, BB. AA., Aguilar, $1960^{2}$.

Serrano Asenjo, Enrique, «La invención del 27 desde dentro: El caso de Ángel del Río», en L. Romero Tobar (ed.), 2004, p. 369-390.

- «Historia y punición: Ángel Valbuena Prat, depurado», Revista de Literatura, 135, 2006, p. 249-259.

Soria Olmedo, Andrés, Fábula de fuentes. Tradición y vida literaria en Federico García Lorca, Madrid, Residencia de Estudiantes, 2004.

Urrutia, Jorge, "Vitalidad de La deshumanización del arte», Revista de Occidente, 300, 2006, p. 5-22.

Valbuena Prat, Ángel, Teófilo. Esbozo de una vida 1898-1925, Madrid, Tipografía de J. Pérez, 1926.

- $2+$ 4. Relatos de misticismo y de ensueño, Madrid, Nuevos Novelistas Españoles, 1927.

- «Centenarios», La Rosa de los Vientos, 2, mayo 1927 a, p. 10.

- «Comentarios de un viaje a Granada», La Rosa de los Vientos, 3, junio 1927 b, p. 3.

- "Góngora, Soledades, editadas por Dámaso Alonso", La Rosa de los Vientos, 2, mayo 1927 c, p. 17.

- «Prólogo», en Pedro Calderón de la Barca, Autos sacramentales II, Madrid, Ediciones La Lectura, 1927 d, p. VII-LXXX.

- «Invierno», Meseta, 6, 1928, p. 10.

- La poesía española contemporánea, Madrid, CIAP, 1930. 
EL VEINTISIETE PROPIO Y EXTRAÑO DE ÁNGEL VALBUENA PRAT

- «Madrigal sin pretensiones a Greta Garbo. Poema de vía estrecha», Europa. Revista mensual internacional, 1, 1933.

- Historia de la literatura española, Barcelona, Gustavo Gili, 1937, 2 vols.

- Dios sobre la muerte. Poemas. Soliloquio a través de una vida 1914-1939 A. V., Barcelona, Apolo, 1939.

- El sentido católico en la literatura española, Zaragoza, Partenón, 1940.

- «La generación de 1927 vista al cabo de veinticinco años», Correo Literario, 1-11-1953, p. 12.

- La literatura española en sus relaciones con la universal, Madrid, Sociedad Anónima Española de Traductores y Autores, 1965.

- Historia de la literatura española, Barcelona, Gustavo Gili, 1968, 4 vols.

- Literatura castellana. Los grupos geográficos y la unidad literaria, Barcelona, Juventud, 1974-79, 2 vols.

- Historia de la literatura española, ed. María Pilar Palomo y Antonio Prieto, Barcelona, Gustavo Gili, 1983², 6 vols.

Valdés, Mario J., "Rethinking the History of Literary History», en L. Hutcheon y M. J. Valdés (eds.), 2002, p. 63-115.

White, Hayden, Tropics of Discourse. Essays in Cultural Criticism, $1^{\text {a }}$ ed. 1978, Baltimore and London, The Johns Hopkins UP, 1986.

- El contenido de la forma. Narrativa, discurso y representación histórica, ed. original 1987, Barcelona, Paidós, 1992. 
